\title{
Discursos sobre el otro. Pasos hacia una arqueología de la alteridad étnica
}

\author{
Cristóbal Gnecco
}

"Los seres humanos son incapaces de decir quiénes son sino pueden alegar que son otra cosa". José Saramago, Historia del cerco de Lisboa

\begin{abstract}
Since Said and Foucault, texts are not seen as mediation anymore, but as realityconstruction devices. Those who represent cannot escape representation. The archeology of alterity takes us away from spectacles of representation and makes us part of them. This essay is a contribution to an archeology of ethnic alterity through an analysis of the systems that have (auto)represented it. For this purpose the author analyses the construction of the relationship between the self and the other through the discourses and representations of colonialism, which enables us to observe the power relationships and exclusions that they developed.
\end{abstract}

El desdibujamiento de la alteridad por los movimientos diaspóricos y su precisión simultánea por la retórica multicultural, junto con la crisis y disolución localizada de algunas esferas constitutivas de los Estados nacionales, ha desatado nuevas definiciones del yo y el otro: movimientos xenófobos; leyes anti-inmigración y disposiciones abiertamente segregacionistas; tratados de libre comercio que permiten el flujo de capitales pero obstaculizan el flujo de individuos; nuevas constituciones que suponen nuevos ordenamientos sociales. La apología multicultural de las diferencias culturales resulta cómoda al nuevo orden del capital, haciendo que las amenazadas fronteras de la mismidad vuelvan a ser establecidas mientras se asegura el acceso a la potencialidad económica de los saberes tradicionales. La promoción de la heterogeneidad que hace el orden multicultural reconoce las demandas subalternas y los logros políticos de 
los movimientos sociales, pero también sirve bien los propósitos de establecer nuevas diferencias o re-establecer las que parecían haberse desdibujado. Por eso la cartografía del surgimiento, despliegue y transformación de los discursos sobre la alteridad contribuye a construir edificios mnemónicos que nos recuerdan qué tan frágiles resultan los tejidos de la vida social y cuánto podemos hacer desde la disciplinas sociales para entender e intervenir su trama.

Este artículo pretende contribuir a una arqueología de la alteridad étnica desde el análisis de los sistemas que la han (auto)representado. El análisis de los sistemas de representación de la alteridad forma parte del interés de las disciplinas sociales por historizar su práctica, un intento deliberado por abandonar los criterios de exterioridad y universalismo desde los cuales edificaron sus relaciones con otros sistemas de representación. El representador no puede escapar de la representación. La arqueología de la alteridad nos aleja del espectáculo de las representaciones para llevarnos a formar parte de ellas. ${ }^{1}$ Este texto también es representación; no el lugar en el cual las representaciones se realizan y adquieren autonomía sino un elemento más en el edificio retórico que hace la alteridad y sus relaciones.

La obra pionera de Edward Said (2004) sobre el oriente mostró cómo la textualización crea un referente de realidad que contribuye a la estructuración de las relaciones intersociales y cómo tiene consecuencias determinantes en la arena política. Después de Said y Foucault el texto ya no se ve como m ediación sino como lugar de construcción de realidad. En la misma dirección Michel-Rolph Trouillot (1995:29) diferenció dos niveles de historicidad, uno referido a la "materialidad del proceso socio-histórico" y otro a "las narrativas". Para los positivistas los dos niveles de historicidad están nítidamente separados, de manera que el proceso (lo que realmente ocurrió) aparece en la narrativa (lo que decimos que ocurrió); la verdad de la historia radica en el acuerdo que exista entre uno y otra. Los constructivistas, en cambio, creen que el proceso está en la narrativa (jamás fuera de ella) porque la realidad no existe más allá de su representación; no existe verdad porque tampoco hay acuerdo. Trouillot propuso un enfoque a medio camino: el proceso existe pero no puede ser entendido sin su representación. Además, la relación entre los niveles de historicidad es doblemente recursiva: (a) el proceso sólo es proceso porque existe la narrativa y ésta sólo tiene relevancia porque existe el proceso; ${ }^{2}$ y (b) uno y otra se

1 "Fichte lo dice de este modo: 'El concepto de un ser que, desde cierto punto de vista, debe presentarse independientemente de la representación tiene, no obstante, que deducirse de la representación, puesto que sólo puede ser por ella.' El círculo es inevitable: no se puede salir de la representación para asistir, desde afuera, al mecanismo de su producción" (Enaudeau, 1999: 28).

${ }^{2}$ Esta afirmación puede ser asimilada al dictum sociológico de que las representaciones son hechos sociales: "A partir de Durkheim y los aportes del grupo de la revista Années Sociologiques los antropólogos han aprendido a concebir las representaciones colectivas como hechos sociales, es decir, considerándolas trascendentes de la voluntad individual, cargadas con la fuerza de la moral social y, en definitiva, como realidades sociales objetivas" (Appadurai, 2001: 20). 
transforman mutuamente y esa transformación es abierta (en tanto interminable). La narrativa determina la existencia del proceso y, al mismo tiempo, ésta determina a quien realiza la narrativa: el proceso construido en la narrativa también constituye a quien lo enuncia y a quien es enunciado (cf. Said, 2004). La ruptura epistemológica entre verdad (el proceso) y ficción (la narrativa) ocurre en la evaluación social (históricamente situada) de narrativas específicas, es decir, en el valor otorgado por los actores sociales a una(s) narrativa(s) a expensas de otra(s):

En algún momento, por razones que son históricas y rodeadas por controversia, los colectivos experimentan la necesidad de imponer una prueba de credibilidad a ciertos eventos y narrativas porque les importa si estos eventos son falsos o verdaderos, si estas historias son hechos o ficciones. Que sea importante para ellos no quiere decir que sea importante para nosotros (Trouillot, 1995: 11).

Trouillot reclamó la distinción y, simultáneamente, la superposición entre los dos niveles de historicidad. Entre los extremos positivista y constructivista no propuso establecer qué es la historia sino cómo trabaja:

[...] la historia sólo se revela a través de la producción de narrativas específicas. Lo que más importa son los procesos y las condiciones de producción de esas narrativas. Sólo el énfasis en el proceso puede descubrir la forma como se relacionan los dos lados de la historicidad en un contexto particular. Sólo a través de esa superposición podemos descubrir el ejercicio diferencial del poder que hace posible algunas narrativas y silencia otras (Trouillot, 1995: 25).

Los argumentos de Trouillot no se limitan a la historia; cubren cualquier producción social de sentido. En el caso que me ocupa cubren las representaciones de la alteridad étnica: éstas representan la realidad tanto como la crean. La relación entre el yo y el otro, entre mismidad y alteridad, es multiforme; sin embargo, sus muchos sentidos se pueden capturar a lo largo de dos vectores opuestos: atracción y reacción. El primero, que opera en el terreno de los saberes de las semejanzas, puede ser descrito con dos conceptos: el deseo civilizador (Elias, 1993) y la simpatía (Foucault, 1985). El deseo civilizador, una erótica política, impone una violencia sobre el otro, impone (hegemónicamente) ser como "yo". El proceso civilizador (modernizador, desarrolista) es un proceso de atracción y es, en este sentido, un proyecto moral.

La simpatía es un ejemplo de lo Mismo tan fuerte y tan apremiante que no se contenta con ser una de las formas de lo semejante; tiene el peligroso poder de asimilar, de hacer las cosas idénticas unas a otras, de mezclarlas, de hacerlas desaparecer en su individualidad -así, pues, de hacerlas extrañas a lo que eran. La simpatía transforma. Altera, pero siguiendo la dirección de lo idéntico [...] (Foucault, 1985: 32). 
La atracción no opera solamente como un yo ejemplar que atrae y otro que es atraído. También opera en sentido contrario. El yo es constantemente atraído por el otro debido a dos razones: (a) el otro encarna las características que el aparato biopolítico de la modernidad condenó y reprimió en el yo ejemplar (libertad natural, instinto, emoción) y que éste ansía y desespera por no tener; y (b) las características negativas del otro son esencialmente poderosas (y por lo tanto potencialmente liberadoras) porque amenazan la fragilidad y el temor generalizado del yo (que teme la cercanía del otro, su contagio). El otro tiene el poder de amenazar al yo, mucho más fuerte (y temido) que el poder que tiene el yo para someter al otro. Para contrarrestar ese miedo, más que para someter, el yo despliega una violencia generalizada sobre el otro. Michael Taussig (1987) lo llamó espacio de la muerte, una violencia impermeable y totalizante que no obedece a lógica distinta al carácter neutralizante del temor al otro. ${ }^{3}$ La irreductibilidad de la violencia colonial fue capturada por Joseph Conrad (1980) en el Corazón de las tinieblas. El polo más frágil y débil (y, en consecuencia, violento) de la relación colonial es el yo. Marlow, el narrador del libro, lo dijo de esta forma:

[...] hay en todo ello una fascinación que comienza a trabajar en él. La fascinación de lo abominable. Podéis imaginar el pesar creciente, el deseo de escapar, la impotente repugnancia, el odio (Conrad, 1980: 15).

Un conocido de Marlow se refería a los aborígenes como enemigos (Conrad, 1980: 29). El otro es el enemigo del yo, aún antes de entrar en contacto. La definición ontológica del otro presupone su maldad esencial. Esta atracción negativa (por contraste con la atracción positiva que ejerce el deseo civilizador) es reprimida por la modernidad y el colonialismo, por igual, porque pone en peligro el vínculo que une al yo con la civilización. Esa represión se ejerce levantando límites que impiden que el yo se dirija al territorio (ontológico) del otro. Yo y otro están delimitados y separados. El yo se encierra en un edificio retórico y práctico, una suerte de aislamiento preventivo que evita que la existencia del otro se constituya en una fuente de referencia tan poderosa que abata las frágiles amarras del barco civilizado. La transgresión no sólo es evitada sino castigada. El yo es un Ulises amarrado al mástil para evitar la atracción inefable de las sirenas, ese otro símbolo de la alteridad.

El otro vector a lo largo del cual se constituye la relación yo-otro es la reacción, la diferenciación, la movilización activa, creativa y deliberada de las diferencias. Por eso la clave para entender los discursos sobre el otro es la relación entre

\footnotetext{
${ }^{3}$ Las explicaciones eco-funcionales, a la guisa de Marvin Harris, como las que hizo Roger Casement (1997) en su reporte sobre el exterminio indígena en el Putumayo en la época del auge del caucho, son gestos reduccionistas vacíos.
} 
colonialismo y modernidad: mientras el colonialismo (externo e interno) subyugó a la alteridad y la mantuvo a distancia, la modernidad demandó su inclusión retórica a partir de una ética igualitaria. Los discursos y prácticas creados por esa articulación contradictoria despliegan una tensión esencial entre atracción y repulsión. Una de las fuentes más determinantes de conflicto en el tratamiento y construcción de la alteridad es la exclusión, el establecimiento de límites que posibilitan la emergencia y sostenimiento de relaciones de poder. Los bordes de exclusión son esenciales para la subordinación de la diferencia. Nader (1996) escribió al respecto:

¿Qué tienen las fronteras que las hace importantes para las relaciones de poder? Un estilo favorecido por contrastes incluye algunas cosas, excluye otras y crea jerarquías [...] las batallas de las fronteras sobre lo que debe ser incluido y lo que debe ser excluido son generalmente arbitrarias, rara vez neutrales y siempre poderosas (Nader, 1996: 2-4).

\section{La constitución de la vida social}

La alteridad supone diferencia, pero menos como lugar de distinción en sí misma que como locus especular invertido -o pervertido, en uno de los sentidos de pervertere, es decir, trastornado, volteado- desde la cual se configura el yo. La alteridad no es constatativa sino un dispositivo de control social de y desde la mismidad; el otro es una categoría política que el orden de la civilización necesita para controlarse a sí mismo. Las relaciones (o, más precisamente, las construcciones) del yo y el otro no son inocentes de poder. La diferencia entre el otro y el yo es jerárquica porque el yo se asume como primario, auto-formado, activo y complejo. El yo es el lugar y origen de la enunciación del otro; el yo es el intérprete y el otro el interpretado. Mismidad y alteridad se co-producen en el proyecto de la civilización (de la modernidad, del desarrollo). La vida social se edifica, entonces, sobre dos horizontes inextricables: identidad y diferencia. La identidad considerada desde una perspectiva relacional es positiva porque afirma y negativa porque segrega y se construye por oposición, dejando por fuera lo que no es. Alteridad y mismidad no son cosas en sí mismas sino partes de una relación, generalmente mediada por la experiencia colonial.

La vida social ha sido regulada de distintas maneras y por distintas instituciones. Una parte esencial de esa regulación ha sido el establecimiento de una normalidad codificada por la moral y/o por lo legal. El horizonte de lo normal está definido por lo que no es normal. El otro y el yo son resultado de un intercambio simbólico cuya economía política debe ser analizada en casos concretos. El horizonte relacional es constitutivo y fundante de la vida social: 
identidad y alteridad son dos caras de la misma moneda. La alteridad no puede entenderse por fuera de un marco relacional, por fuera de la relación entre prácticas locales y retóricas globales; como señaló Jones (1997):

La construcción de las identidades étnicas y nacionales involucra un diálogo constante entre la reproducción de prácticas culturales localizadas y modos existentes de auto-conciencia cultural con discursos más amplios que buscan producir imágenes "auténticas" de cultura e identidad (Jones, 1997: 103).

Por eso el discurso sobre el otro es inseparable de los proyectos de construcción de identidad.

Los discursos sobre la alteridad étnica están atravesados por dos aspectos centrales entrelazados: son moralizantes y localizantes. Moralizantes porque el proyecto civilizador comporta tres características mínimas, cuya lógica cultural fue construida por la síntesis entre evolucionismo social y darwinismo: a) la civilización moderna es superior; b) esta superioridad supone un imperativo moral: civilizar, modernizar, desarrollar a los primitivos, salvajes, bárbaros, subdesarrollados, tercer-mundistas; c) si este empeño moral encuentra oposición o se concibe como imposible, el uso de la violencia resulta legítimo y el victimario se resignifica en víctima y el sufrimiento de los otros aparece como inevitable (cf. Dussel, 1994). Una de las características más conspicuas del proyecto moderno es su uso de la violencia; la alteridad queda envuelta en las redes retóricas y políticas de una violencia que se despliega en el locus del deber ser y que, en consecuencia, adquiere su legitimidad como parte constitutiva esencial de un proyecto moral.

El proceso civilizador es un proyecto moral violento: el deber ser moderno es un argumento teológico, político, cultural, económico; es decir, una empresa moral total. Por otra parte, el carácter localizante de esos discursos construye el locus espacio-temporal en el cual aparece (o desaparece) la alteridad. Ese locus es determinante en los procesos de la civilización y también en los procesos que la enfrentan y la resisten. En ambos casos el otro es un sujeto lejano en el tiempo y el espacio (un habitante de la naturaleza), aunque este último es un espacio temporal; es decir, el lugar no es un lugar sino un tiempo (la naturaleza temporalizada). Mignolo (1995: xi) argumentó que la colonización y la modernidad establecieron la complicidad entre el reemplazo del otro en el espacio por el otro en el tiempo y la articulación de las diferencias culturales en jerarquías cronológicas. Fabian (1983) llamó a este fenómeno simultáneo de desespacialización y temporalización, que estableció la lógica fundante del orden colonial, negación de la coetaneidad. Por eso uno de los requerimientos 
esenciales de la modernidad fue la existencia de una cronopolítica. Para que el otro (lejano en tiempo y espacio) pudiese ser "atraído" al tiempo moderno (el lugar de la cultura) hubo que universalizar la historia. Para que el otro fuese atraído primero se necesitó su localización en un tiempo-lugar lejano: de esta manera la distancia aparece como un pre-requisito del proyecto civilizador; sin ella ese proyecto no existiría. El discurso espacio-temporal usado por occidente para localizar el espacio-tiempo de la alteridad es un discurso distanciado que ha producido tiempos y espacios marginados de, y colonizados por, el tiempo y el espacio occidentales. Este discurso ha tipologizado temporalidad y espacialidad con categorías políticas más que disciplinarias (como salvaje, primitivo, tribal, mítico). La constitución del otro como sujeto moral necesita un cronotopo porque su atracción es esencial en la moral civilizadora: el distanciamiento es una estrategia discursiva básica en la construcción de la alteridad, de un "otro" localizado en "otro tiempo" y otro espacio que debe ser atraído a nuestro tiempo y lugar, aquellos de la civilización (cf. Fabian, 1983). Sin embargo, el tiempo del otro es un tiempo detenido, un no-tiempo en el cual no ocurren los eventos que la moral occidental asocia con el cambio, el progreso y el desarrollo. El tiempo del otro es natural, ajeno al tiempo trasformado por la cultura. El tiempo natural de la alteridad debe ser conquistado y dinamizado; el tiempo de la cultura civiliza el tiempo del otro. Así, la narrativa maestra en esta historia es una y simple: la alteridad étnica es distinta de la mismidad porque está en otra parte y, sobre todo, en otra época (estática y que debe ser atraída a la nuestra, dinámica y activa). El tiempo y el espacio (temporalizado) devinieron categorías básicas en la racionalización de las diferencias culturales.

\section{La alteridad, parte de una relación colonial}

La alteridad étnica es resultado discursivo del aparato colonial y es "real": siempre hay un yo que enuncia y otro que es enunciado. La alteridad adquiere una significación más precisa -y su movilización política se convierte en un propósito explícito- cuando su construcción ocurre en el marco de procesos de dominación. La alteridad se construye a través de la enunciación globalizante que crea, simultáneamente, lo que es global y lo que es local. Esta es una empresa moral: lo global es el deber ser y lo local lo que debe ser domesticado, extirpado, anexado, marginado. La construcción de la alteridad ha generado conflicto porque la definición del otro en el proyecto moderno ha comportado su categorización como sujeto dominado, como sujeto cuya suerte se decide en una moralidad externa, cuyo pasado, presente y futuro están determinados y dictados por otros. 
En El corazón de las tinieblas Joseph Conrad hizo hablar al yo sobre el otro en el marco de la experiencia colonial. Marlow, el narrador del libro, escribió desde y escribió el colonialismo, un orden sostenido por la confrontación violenta de mismidad y alteridad; aunque esa relación no siempre es colonial -la totalidad de la vida social se edifica sobre esa oposición mínima- adquiere en el colonialismo sus colores más nítidos, sus significaciones más esenciales, sus desgarramientos más insidiosos, el color más rojo de la sangre. En medio de las sombras de un atardecer en el estuario del Támesis, Marlow rememora y sitúa su experiencia con el otro y con sí mismo. Primero está el paisaje, la prefiguración de los seres que lo pueblan:

Un país cubierto de pantanos, marchas a través de los bosques, en algún lugar del interior la sensación de que el salvajismo, el salvajismo extremo lo rodea... toda esa vida misteriosa y primitiva que se agita en el bosque, en las selvas, en el corazón del hombre salvaje. No hay iniciación para tales misterios. Ha de vivir en medio de lo incomprensible, que también es detestable (Conrad, 1980: 15).

Ese paisaje es un mundo lejano, oscuro, exterior al mundo de la civilización. A ese mundo se entra y (con suerte) de él, eventualmente, se sale. Por eso Marlow dijo que "penetramos más y más espesamente en el corazón de las tinieblas" (Conrad, 1980: 68). Después (antes) está el propósito que alienta la constitución de la relación violenta (dominio y subordinación) entre el yo y el otro:

La conquista de la tierra, que por lo general consiste en arrebatársela a quienes tienen una tez de color distinto, narices ligeramente más chatas que las nuestras, no es nada agradable cuando se observa con atención. Lo único que la redime es la idea. Una idea que la respalda: no un pretexto sentimental sino una idea; y una creencia generosa en esa idea, en algo que se puede enarbolar, ante lo que uno puede postrarse y ofrecerse en sacrifio [...] (Conrad, 1980: 15-16).

La dimensión monstruosa y salvaje de la empresa colonial -calificada con los mismos epítetos con los cuales se sitúa al otro en la taxonomía del horrordesaparece ante su dimensión mesiánica: el yo ejemplar y civilizado es el liberador del otro sometido y barbarizado, no importa si esa liberación ocurre con altas dosis de violencia - una de las características esenciales en la configuración del Estado moderno es su monopolio de la violencia, a veces desmesurada; su ejercicio se justifica por el bien común. Kurtz resumió esta concepción de una manera lapidaria: "Por el simple ejercicio de nuestra voluntad podemos ejercer un poder para el bien prácticamente ilimitado" (Conrad, 1980: 95). El yo libera, el otro es liberado. La liberación se hace a través de la mimesis y esta se realiza, sobre todo, por el ejemplo -cuyas amarras al mundo real las constituyen la 
educación y la represión. Los salvajes de Marlow pueden llegar a ser pantomimas de la civilización con un poco de entrenamiento:

A ratos tenía, además, que vigilar al salvaje que llevaba yo como fogonero. Era un espécimen perfeccionado; podía encender una caldera vertical. Allí estaba, debajo de mí, y, palabra de honor, mirarlo resultaba tan edificante como ver a un perro en una parodia con pantalones y sombrero de plumas, paseando sobre sus patas traseras. Unos meses de entrenamiento había hecho de él un muchacho realmente eficaz (Conrad, 1980: 71).

La idea (civilización, modernidad, desarrollo, destino manifiesto) exige víctimas sacrificiales. En el altar del sacrificio se ofrecen el otro colonizado -victimario de su dominador pero, sobre todo, víctima de una máquina genociday el yo colonizador, desgarrado y sudoroso, siempre temiendo la omnipresencia del otro. Mientras Marlow "permanecía paralizado por el terror" ante los nativos que encontró en una de las estaciones comerciales en su viaje por el río -a pesar de que ni siquiera repararon en él, destrozados como estaban por el peso de la máquina colonial- se llenó de felicidad al ver a un europeo, al encontrarse con sí mismo en la figura de un "blanco"; Marlow no pudo hacer nada distinto de estrechar "la mano de aquel ser milagroso" (Conrad, 1980: 35). El otro (y su lugar) son incomprensibles no sólo porque son distintos sino, sobre todo, porque están en otro tiempo (el del salvajismo, el de la oscuridad):

Estábamos incapacitados para comprender todo lo que nos rodeaba; nos deslizábamos con fantasmas, asombrados y con un pavor secreto, como pueden hacerlo los hombres cuerdos ante un estallido de entusiasmo en una casa de orates. No podíamos entender porque nos hallábamos muy lejos y no podíamos recordar porque viajábamos en la noche de los primeros tiempos, de esas épocas ya desaparecidas (Conrad, 1980: 69).

Desde un punto de vista constructivista las identidades étnicas son producto del colonialismo debido al desplazamiento y la fragmentación de formaciones de asociación pre-existentes y la imposición de nuevas alteridades (cf. Clifford, 1992; Friedman, 1994). Visto de esta manera, el orden colonial no es un fenómeno totalizante que devora todo a su paso, suprimiendo culturas por doquier desde su aparato militar, religioso, educativo y administrativo; debe entenderse, más bien, desde (a) la co-existencia de lenguajes, memorias, espacios y tiempos; y (b) la lógica que permite que uno de los sectores co-existentes se imponga sobre los demás. Aunque la cultura del dominador se vuelve sinónimo de lo real y establece el asiento del poder, no suprime la totalidad de las experiencias culturales de los otros; el resultado es una semiosis que co-produce hibridaciones y mestizajes. Las identidades étnicas contemporáneas se forjaron en la relación colonial con la hegemonía; no provienen de una esencia inmutable si no de una 
acomodación estratégica a complejas relaciones de subordinación, resistencia y auto-afirmación.

\section{Representación del otro y lógicas culturales}

Foucault (1985) argumentó que la episteme renacentista, aquella en la que se enmarcó el "descubrimiento" de América y los dos primeros siglos de la conquista, estuvo marcada por la búsqueda de las semejanzas:

Buscar el sentido es sacar a la luz lo que se asemeja. Buscar la ley de los signos es descubrir las cosas semejantes. La gramática de los seres es su exégesis. [...] La naturaleza de las cosas, su coexistencia, el encadenamiento que las une y por el cual se comunican, no es diferente a su semejanza. Y ésta sólo aparece en la red de los signos que, de un cabo a otro, recorre todo el mundo (Foucault, 1985: 38).

Esta episteme de lo semejante no podía imaginar seres "distintos", excepto si estos se localizaban en un plano en el que esa "diferencia" los alienara de los demás y, por lo tanto, los hiciera auténticamente "otros". No de otra manera puede entenderse la discusión teológica del siglo XVI (Vitoria, Ginés, Las Casas): la solución fue negar a los indígenas el alma y, por lo tanto, su condición de semejante. Tampoco se les otorgó la posibilidad de comunicación: los otros eran mudos. El "orden” renacentista no es un orden sino, solamente, un sistema de exclusión simple y problemático, de otro modo la disputa teológica no hubiese sido tan acrimoniosa y prolongada. En esta episteme no había clases, sólo sujetos semejantes (todos los "hombres") y seres diferentes -como los animales, semejantes entre sí, a los que se hicieron pertenecer los indígenas.

Nada de eso ocurrió después, al final de la colonia, cuando ya estaba configurada la episteme clásica, la episteme del orden basada en identidades y diferencias - la semejanza ya había sido expulsada a los márgenes del conocimiento. Entonces surgieron todas las clases de seres humanos (blancos, negros, zambos, etc), todas las categorías que habrían de adquirir estatus ontológico. De esta manera se configuró la estructura de la sociedad clásica, una estructura estamental rígidamente compartimentalizada y ordenada que permite definir qué es y qué no es, es decir, definir tanto al yo como al otro:

[...] a partir del siglo XVII ya no puede haber más signos que los que se encuentran en el análisis de las representaciones, según las identidades y las diferencias. Es decir, toda designación debe hacerse de acuerdo con 
una cierta relación con todas las otras designaciones posibles. Conocer lo que pertenece como propio a un individuo es tener para sí la clasificación o la posibilidad de clasificar el conjunto de los otros. La identidad y lo que la marca se definen por el resto de las diferencias. Un animal o una planta [o una persona] no es lo que indica -o traiciona- el estigma que se descubre impreso en él; es lo que no son los otros; no existe en sí mismo sino en la medida en que se distingue (Foucault, 1985: 145).

Así, la alteridad -esa parte de una dicotomía que se define tanto por lo que es como por lo que no es- no aparece antes de la configuración de la episteme clásica en el siglo XVII, antes de esa época no podemos hablar de alteridad sino de desemejanza. Con la episteme clásica el otro aparece como diferente, menos como lugar de distinción en sí mismo que como locus especular desde el cual se configura el yo; el otro es un lugar de control del yo, una categoría política que se le impone, el lugar donde se deposita la basura simbólica del yo, todo lo que no debe ser: salvaje, incivilizado, irracional. El otro no es constatativo sino una necesidad en el control social de la mismidad. Por eso en la estructuración de la vida social desde el siglo XVII mismidad y alteridad son inseparables.

Con la episteme moderna apareció otro elemento fundamental para la descripción de los discursos sobre el otro: la organización. Ella hizo posible el surgimiento de las jerarquías y el establecimiento de las funciones de cada una de las clases. De esa manera surgieron en el horizonte de la episteme moderna marcos de organización que hicieron posible esa homogeneidad funcional. En el terreno de las identidades ese rol fue cumplido por la nación; en el del saber, por la ciencia. La organización de los sujetos (del yo y del otro) fue realizada por los saberes modernos desde el criterio de exterioridad y de trascendencia. El discurso sobre el otro se basa en la exterioridad, pero el discurso mismo no tiene exterior; desde la historia, la antropología o la sociología el horizonte de los seres humanos se organizó de acuerdo a conceptos trascendentes como raza, cultura y etnia. La taxonomía moderna dispuso la aparición de un orden basado en la organización en el que los seres humanos encontraron su lugar en el juego de las diferencias y las identidades. Antes de la modernidad esta organización trascendente no hubiese sido posible -no hubiese sido posible, por ejemplo, la antropología.

La liberación del individuo -tanto económica como cultural- que surge del individualismo desatado por la Reforma es la marca de fábrica de la modernidad. De esa liberación surge la otra gran idea moderna, la igualdad. Individuo e igualdad aparecen como condición sine qua non de la vida moderna. La construcción de la alteridad en los dos últimos siglos está atravesada, signada y determinada por el proyecto moderno, la extensión del proyecto civilizador cuya 
moralidad supone una condena -retórica o de hecho, pero siempre violenta- de todo aquello que se opone a su realización. La modernidad implica una disolución del otro a través de su atracción. Paradoja: el otro, que se requiere de manera determinante en la constitución de la mismidad moderna (en tanto proyecto), busca ser constantemente disuelto porque la igualdad aparece en el horizonte de la episteme moderna como una condición central de la construcción social. Esa tensión esencial explica la co-producción entre modernidad y colonialismo (sensu Quijano, 1990; Dussel, 1994; Castro, 2005). La utopía moderna pensó un orden horizontal basado en dos pilares retóricos: el individuo libre y la igualdad. Sin embargo, la expansión mundial del mercantilismo (primero) y del capitalismo (inmediatamente después) se edificó sobre el colonialismo, es decir, sobre la creación de un otro externo a (y atraído por) un yo civilizado y ejemplar. Los Estados nacionales de Europa eliminaron las diferencias dentro de sus fronteras creando identidades nacionales, pero las erigieron y las discriminaron en sus dominios coloniales. La modernidad se predicó desde una igualdad retórica dentro de los límites de los Estados nacionales imperialistas y desde una discriminación violenta contra la diferencia en las colonias. Las relaciones entre colonizadores y colonizados no fueron igualitarias ni horizontales. Tampoco lo fueron las relaciones sociales al interior de las sociedades subalternas; esta segunda asimetría se llama endocolonialismo. Colonialismo y endocolonialismo son las formas de eliminación de la utopía de horizontalidad moderna.

El orden colonial está basado en el principio europeo del siglo XVII de una sociedad estable y jerárquica modelada en el orden cósmico; esta disposición especular ha sido llamada cosmopolis (Toulmin, 2001). En este modelo de sociedad los segmentos sociales estaban jerárquicamente dispuestos, tanto como los cuerpos del cosmos, por un orden divino que proveía una estabilidad natural y ahistórica. Esta arquitectura social fue el objeto contra el cual se realizó la revolución burguesa del siglo XVIII y fue reemplazada por la sociedad moderna. Sin embargo, la extinta cosmopolis no desapareció sino que fue destinada a alimentar el orden colonial. Aníbal Quijano (1990) sostiene que la modernidad se escindió, desde finales del siglo XIX, en dos racionalidades distintas: una dominada por la razón instrumental y otra por la razón histórica, la verdadera y genuina forma de la modernidad. Esta última, edificada sobre la unión entre razón y liberación, fue superada y articulada a la razón instrumental a través de la experiencia colonial. 


\section{En el bazar de las dicotomías}

La alteridad étnica no es una entidad en sí misma sino parte de una relación colonial activamente mediada (Taussig, 1993: 130). El colonialismo no existe sin la relación jerárquica entre el yo y el otro (nosotros/los otros; mismidad/ alteridad) que descansa sobre otras dicotomías que la dotan de sus cambiantes sentidos históricos. En este apartado exploraré tres de ellas: racionalidad/ irracionalidad, cultura/naturaleza y bien/mal.

\section{Racionalidad/irracionalidad}

La razón parasita lo que Bernstein (1983: 16-20) llamó “ansiedad cartesiana”, esto es, el temor a que todo lo que se aventure por fuera de la razón, por fuera de un marco de referencia universal y transhistórico, nos precipite en el caos y la locura. Pero como Gadamer (1992) indicó, la razón también es histórica y contextual y deriva su poder de tradiciones culturales específicas; la razón no es universal ni transcultural. La ansiedad cartesiana es infundada y la oposición entre racionalidad/irracionalidad aparece como una de las dicotomías históricas sobre las que funda su sentido la representación de la alteridad; sin embargo, su estructura discursiva es poderosa y ha naturalizado su historicidad. La antropología, por ejemplo, cree que los actores sociales están atrapados en la cultura y ha exagerado el impacto de los símbolos dominantes o las ideologías sobre los sujetos (Giddens, 1979: 72). Así ha provisto buena parte de la munición teórica de esta dicotomía porque pretende ser el estudio racional de la cultura y sólo es "racional" la antropología de la cultura y no la cultura misma, la racionalidad de esta última no es sino una racionalidad conferida y nunca por sí (Leclerq, 1973: 36-37). El yo (la antropología, la racionalidad occidental) es la luz y el otro la oscuridad, un sujeto atrapado en un bosque de símbolos que le resulta incomprensible. Fabian (1983) señaló al respecto:

La verdad y la conciencia consciente [conscious awareness] están alineadas aquí con el conocedor, el antropólogo; el disimulo [dissimulation] y la caída en los poderes de la inconciencia están en el lado del Otro. No es sorpresivo que la noción teórica de un inconsciente cultural y la prescripción metodológica que va con ella se conviertan, fácilmente, en esquemas para influenciar, controlar y dirigir a los Otros (Fabian, 1983: 51-52).

Esta dicotomía adquiere, ocasionalmente, un ligero matiz que opone razón a emoción, uno de los más importantes fundamentos de la cosmovisión moderna. 
La sociedad moderna que emergió del racionalismo del siglo XVII consagró el dominio de la razón (patrimonio del individuo pensante) y condenó la emoción. ${ }^{4}$ Así la emoción fue desterrada al ámbito privado, el espacio de la alteridad femenina; los hombres, en contraste, cuyo espacio era la esfera pública, no sólo sostenían la razón sino que no podían permitirse el sentimentalismo femenino. De esta manera se inscribió sobre la superficie del cuerpo individual el control político del cuerpo social: la transgresión emocional fue cuidadosamente reprimida con la moral puritana -la separación taxativa y domesticada, sobre todo por la educación religiosa, del placer y el sexo- y, sobre todo, con la penalización moral y legal del tráfico sexual interestamental; de hecho, la jerarquía y la estabilidad no podían permitir el socavamiento del Estado clasista. "De todos los sentimientos humanos fuertes la emoción sexual parecía la más grave de las amenazas contra la naciónEstado jerárquica" (Toulmin, 2001: 211). Este control político de la sexualidad no se tradujo en una devaluación del eros sino en su represión. Sólo hasta la revolución de los derechos civiles en la década de 1960 el erotismo recuperaría el lugar perdido y se convertiría en un arma poderosa de transgresión política.

La alteridad étnica fue la otra gran depositoria de lo emocional. Los otros (los indígenas, los afrodescendientes) fueron transgresores potenciales por su debilidad innata, por su lascivia, por su promiscuidad, es decir, por su emocionalidad. Las crónicas coloniales y la literatura decimonónica y de principios del siglo XX están llenas de observaciones sobre la "emocionalidad" del otro étnico. Bolaños (1994) mostró cómo los indígenas americanos fueron feminizados con el propósito de inscribir, aún más, las marcas de la dominación:

La negación de la calidad de "varón" en el indios desde finales del siglo $\mathrm{XV}$ y principios del XVI corresponde a una proyección del sentido de dominio de una Europa vista como varonil, activa, recta y expansiva sobre una América vista como pasiva, corregible, vacía, virgen y asociada siempre con lo débil (1994: 138).

El territorio de los otros, botín de conquista, asumió las características acordadas a la mujer en el discurso androcéntrico. La mujer y el otro étnico fueron localizados en un lugar equivalente de potencialidad lasciva, una amenaza para el mundo racional androcéntrico. Como en otras características ontológicas del otro, en este aspecto se puede rastrear su estela en el tiempo, mucho antes de que los conquistadores europeos siquiera encontraran al primer nativo americano. Bartra (1998) señaló el carácter lascivo y femenino (lascivia natural y éxtasis salvaje) del otro en el mundo clásico. La mitología griega está plagada

\footnotetext{
4 "Descartes exaltó la capacidad para la racionalidad formal y el cálculo lógico como el elemento supremamente "mental" de la naturaleza humana a expensas de la experiencia emocional, lamentable subproducto de nuestras naturalezas corporales" (Toulmin, 2001: 209).
} 
de figuras lascivas y exaltadas, como las ninfas y las ménades, que forman en los rangos de la alteridad; además, la ritualización de la vida social estuvo basada, en buena parte, en la caracterización positiva del yo y la derogación del otro a través de la transposición burlesca de sus papeles:

Los populares rituales dionisíacos provocaron la gran diseminación del mito del hombre salvaje en Europa y contribuyeron a consolidar muchos de los rasgos iconográficos y de los mitemas que lo caracterizan en sus ulteriores versiones medievales, renacentistas y modernas: lascivia, canibalismo, ingestión de carne cruda, comportamiento animal, peculiaridades bestiales (desnudez, piel vellosa, cola, patas equina, etcétera), gusto incontrolable por el vino, rechazo a la sociabilidad “normal." Habría que agregar los adornos vegetales (hiedras usadas por ménades y bacantes) y el garrote o tronco como arma y como símbolo (Bartra, 1998: 27).

Esta dicotomía tiene una variación significativa, espiritualidad/materialismo, en la cual los términos de la relación se invierten: la espiritualidad del otro aparece como un activo cultural positivo que se opone al materialismo negativo y condenado de los otros (los blancos). Aunque los antecedentes de esta retórica pueden encontrarse en los documentos de los defensores de indios e impugnadores de encomenderos en el siglo XVI, la primera manifestación de esta dicotomía en Colombia emitida por un indígena fue el manifiesto de Quintín Lame (2004). Después los antropólogos densificaron el argumento: la espiritualidad indígena -que lleva, según la idea, a los grupos nativos a mantener una relación armónica y de equilibrio con sí mismos, con los demás y con la naturaleza- es cualitativamente superior al materialismo occidental. En un artículo sobre los misioneros y los indígenas Gerardo Reichel-Dolmatoff (1977) escribió:

Al designar a ciertas sociedades con el calificativo de primitivas deshonramos al indio americano, pues al usar ese término tomamos como único criterio el bajo nivel tecnológico y el poco rendimiento económico de estas sociedades [...] aún en las sociedades tecnológicamente más atrasadas la vida espiritual del indígena, sus ideaciones abstractas y sus códigos morales pueden alcanzar niveles muy altos de elaboración y complejidad [...] debemos reconocer con toda sinceridad que el indígena -mal designado como colombo-salvaje- ha creado y sigue creando valores espirituales que bien podrían ser un ejemplo para muchos que se vanaglorian de pertenecer a una sociedad civilizada (Reichel-Dolmatoff, 1977: 422) 


\title{
Cultura/naturaleza
}

La localización polar de las categorías naturaleza y cultura ha alimentado la definición de un amplio campo semántico colonial en el cual los dos invitados centrales son la alteridad y la mismidad, el otro y el yo. El primero se identifica con la naturaleza, el segundo con la cultura. La historia de la civilización ha sido la historia de la lucha de la cultura contra la naturaleza, la domesticación de la libertad natural y su reducción al orden cultural. Marlow se expresó así sobre la naturaleza africana:

\begin{abstract}
¿Qué éramos nosotros, extraviados en aquel lugar? ¿Podíamos dominar aquella cosa muda o sería ella la que nos manejaría a nosotros [...] La tierra no parecía la tierra. Nos hemos acostumbrado a verla bajo la imagen encadenada de un monstruo conquistado pero allí [...] allí podía vérsela como algo monstruoso y libre (Conrad, 1980: 51, 70).
\end{abstract}

En esa dicotomía la naturaleza se antropomorfiza en la piel del otro y se convierte en el lugar del temor, ${ }^{5}$ en la amenaza frente a la debilidad del yo:

Miré a mi alrededor y, no sé por qué, puedo aseguraros que nunca antes, nunca, aquella tierra, el río, la selva, la misma bóveda de ese cielo tan resplandeciente me habían parecido tan desesperados y oscuros, tan implacables frente a la debilidad humana (Conrad, 1980: 107).

Ante la "debilidad humana" la cultura se enfrenta a la naturaleza para domesticarla. La modernidad tendió hacia la disolución de la naturaleza hasta la aparición de los discursos ecologistas de la era multicultural. La historia edificada sobre una dicotomía (occidental) buscó disolverla para instaurar el orden de la cultura. La trayectoria del deseo civilizador es un largo viaje hacia la desaparición ontológica de la naturaleza. El objetivo de la racionalidad es desenajenarse de la naturaleza, que es vista como un lugar que amenaza con destruir y desestabilizar la cultura. Lo natural es lo ilimitado, lo desordenado, lo instintivo, lo emotivo, aquella moralidad negativa que el deber ser moderno reprime y penaliza. Desde el inicio del régimen colonial la alteridad étnica fue racionalizada y construida en el discurso a partir de esta dicotomía moral: la cultura era positiva, ejemplarizante; los indígenas, en cambio, eran parte de la naturaleza. ${ }^{6}$

\footnotetext{
${ }^{5}$ Helms $(1988,1991)$ mostró la ocurrencia transcultural y transhistórica de la significación de lo diferente (a medida que las culturas se alejan en los viajes del centro o axis mundi, donde todo es conocido) como sobrenatural, mítico, místico e ideológicamente poderoso. Se teme al otro porque significa el poder de lo no domesticado, la naturaleza (cf. Taussig, 1987).

${ }^{6}$ Mignolo (1995: 266) mostró que la cartografía de América en los siglos que siguieron a los viajes de Colón está ilustrada con animales salvajes y gente desnuda viviendo en la selva, las características de la terra nova, la marca de la naturaleza. La situación no fue muy distinta en épocas posteriores. En un mapa de 1639 cada continente está representado por una mujer: "Europa y Asia están representadas por mujeres bien vestidas, mientras Africa y América lo están por mujeres semi-desnudas”. Esto no es todo. La mujer europea está sentada en algún objeto, probablemente una silla que no se ve, mientras la mujer asiática está sentada en un camello (un animal doméstico) y la africana y americana en animales salvajes (un cocodrilo y un armadillo).
} 
Desde la Conquista la alteridad fue localizada más allá de los cuidados límites de la razón -el otro era monstruoso y animal- y más allá de los límites de la vida urbana, sedentaria y "en policía"; el otro era el habitante salvaje de la selva, de la naturaleza, del caos primigenio, del calor y la podredumbre. Sin embargo, el otro nunca perdió su carácter humano. La dominación colonial degrada la humanidad del otro, lo animaliza, pero para que esto ocurra el otro debe ser, antes que nada, humano:

En su forma humana o casi humana los indios salvajes reflejan mejor en el colonizador proyecciones vastas y barrocas de un salvajismo humano. Y fue solo porque los indios salvajes eran humanos que pudieron servir de fuerza de trabajo -y como sujetos de tortura; porque no sólo la víctima como animal gratifica al torturador sino el hecho de que la víctima es humana, permitiendo que el torturador se vuelva salvaje (Taussig, 1987: 83).

Marlow lo narró así de manera abundante:

$[\ldots]$ y los hombres eran [...] No, no se podía decir inhumanos. Era algo peor, sabéis, esa sospecha de que no fueran inhumanos. Aullaban, saltaban, se colgaban de las lianas, hacían muecas horribles, pero lo que en verdad producía estremecimiento era la idea de su humanidad, igual que la de uno, la idea del remoto parentesco con aquellos seres salvajes, apasionados y tumultuosos (Conrad, 1980: 70).

El otro étnico es en todo animal (aulla, salta, pende de los árboles, hace muecas) pero es, finalmente, humano. Esa certeza produce horror. Una característica esencial de esta dicotomía es considerar la naturaleza como límite y la cultura como posibilidad de superarlo. La idea de la determinación de la naturaleza sobre la cultura surge de una vieja tradición europea, quizás de cientos de años pero exacerbada con el enfrentamiento colonial desatado por la conquista de América. Así se construyó una narrativa que ha perdurado hasta ahora: la identificación del clima con el territorio y su influencia sobre "los seres organizados". En la escalera evolutiva los climas temperados, exigentes y extremos, modelaban a los seres humanos de tal manera que el progreso técnico era la única posibilidad de sobrevivencia. En la feracidad de los trópicos, en cambio, el calor y la abundancia modelaban seres atávicos y poco dados a las artes de la superación. El clima-territorio apareció en la ondulación del discurso como condición y limitante de los sujetos. El clima-territorio del otro asumió una impronta que no ha abandonado: decrepitud, podredumbre, decadencia. La literatura sobre el trópico abunda en este tema, una suerte de fatalismo por haber nacido allí, una determinación sobre el carácter, una valoración negativa 
y fatalista. La obra del poeta Álvaro Mutis es paradigmática en este sentido. En ella la determinación:

[...] solo cobra sentido en relación con el clima que se respira: un vaho de tierra caliente que impregna el conjunto, algo vivo que no sólo emana de la geografía y recubre los seres, nutriéndolos y degradándolos, sino que actúa y se desenvuelve como una presencia, densa y perceptible [...] Detenida en el sopor inalterable no es sólo una precisión barométrica. Es también un clima moral, un estado de conciencia (Cobo, 1973: 12).

Marlow, ese narrador colonial, lo expresó de esta manera:

A lo largo de aquella costa informe, bordeada de un rompiente peligroso, como si la misma naturaleza hubiera tratado de desalentar a los intrusos, remontamos y descendimos algunos ríos, corrientes de muerte en vida, cuyos bordes se pudrían en el cieno y cuyas aguas, espesadas por el limo, invadían los manglares contorsionados que parecían retorcerse hacia nosotros, en el extremo de su impotente desesperación [...] El gran muro de vegetación, una masa exuberante y confusa de troncos, ramas, hojas, guirnaldas, inmóviles a la luz de la luna, era como una tumultuosa invasión de vida muda, una ola arrolladora de plantas, apiladas, con penachos, dispuestas a derrumbarse sobre el río, a barrer la pequeña existencia de todos los pequeños hombres que, como nosotros, estábamos en su seno (Conrad, 1980: 29, 57).

Otro narrador de la experiencia colonial, Ferdinand Bardamu de Céline, expresó así el efecto del trópico sobre los "blancos" venidos de Europa:

En el frío de Europa, bajo las púdicas nieblas del Norte, salvo las matanzas, sólo se supone la hormigueante crueldad de nuestros hermanos; pero en cuanto les excita la innoble fiebre de los trópicos su podredumbre invade la superficie. Es entonces cuando uno se desabrocha con desvarío y la suciedad triunfa y nos recubre por entero. Es la confesión biológica. En cuanto el trabajo y el frío dejan de astringirnos, aflojan un poco sus tenazas, uno puede ver de los blancos lo mismo que se descubre de la riente orilla cuando el mar se retira: la verdad, charcas pestilentes, cangrejos, carroña y zurullos (Céline, 1984: 88).

Así la selva se humaniza y quienes la habitan adquieren sus características, se funden con ella. ${ }^{7}$ La irreductible determinación natural de la cultura pone al descubierto que sólo el trabajo organizado, junto con el frío, pueden doblegar

\footnotetext{
7 “[La selva] es un enemigo horrible, de muy maligna disposición y malevolencia innata. La vegetación caída que se pudre lentamente llena y espesa el ambiente con sus tufos vaporosos. El indio suave, pacífico y amoroso es sólo una ficción de muy férvidas imaginaciones. Son de una crueldad innata” (Whiffen, 1915).
} 
los instintos más básicos (la confesión biológica) que desatan las condiciones del trópico. Sus pobres habitantes no tienen salvación:

Disimuladas entre las frondas y repliegues de aquel inmenso cocimiento algunas tribus en extremo diseminadas se habían quedado estancadas, aquí y allá, entre pulgas y moscas, embrutecidas por los totems y atracándose invariablemente de mandiocas podridas. Tribus totalmente ingenuas y cándidamente caníbales, enloquecidas de miseria y azotadas por mil pestes. De nada servía acercarse a ellas. Nada justificaba una expedición dolorosa y sin resultado (Céline, 1984: 121-122).

La dicotomía cultura/naturaleza tomó un matiz ligeramente distinto con la modernidad, que marcó la separación entre naturaleza y sociedad. Por eso el discurso científico empezó a "dar cuenta” de la naturaleza (incluida la alteridad) desde un horizonte epsitémico del cual fue desterrada la axiología. Una maravillosa paradoja histórica es que varios siglos de modernidad no acabaron con la discursividad sobre la naturaleza, como podría haberse esperado de la moralidad del proyecto de disolución de la diferencia. Al contrario. Los tiempos que corren, con una lógica cultural distinta llamada postmodernidad y con una organización de los sujetos y de la vida política también distinta, llamada multiculturalismo, no sólo no han acabado con la naturaleza sino que la han elevado a las más altas crestas de la ola. La naturaleza desempeña un papel central en la puesta en escena contemporánea, pone de presente la cadena de errores cometidos y constituye un horizonte utópico. La naturaleza mala del discurso moderno, aquella que debía ser sometida a las bondades de la cultura, viste ahora ropajes buenos. ${ }^{8}$ Mientras el orden moderno creó culturas para deshacer naturalezas, el orden multicultural crea naturalezas donde no hay culturas o donde establece, discursivamente, su inexistencia o limita su aparición. La creación discursiva que Astrid Ulloa (2004) ha llamado nativo ecológico está caracterizada por un esencialismo naturalista que ubica a los otros (sobre todo a los indígenas) en un tiempo detenido (tradicional y ecológico) y en territorios específicos y autónomos -ricos en biodiversidad y en mercancías de alto valor en el mercado actual y, sobre todo, futuro- que se preservan o promueven a toda

\footnotetext{
${ }^{8}$ Esta re-significación discursiva no es unánime. Por ejemplo, la dicotomía cultura buena/naturaleza mala se prolonga en el imaginario militar del conflicto armado colombiano. La estrategia política y militar del Plan Colombia "construye un sentido alrededor de la naturaleza, la define como entidad hostil a ser domesticada, dominada y, en algunos casos, hasta eliminada" (Espinosa, 2002: 87). La declarada función del comandante de la base militar de Tres Esquinas, en el Amazonas, es “domesticar la selva” (citado por Espinosa, 2002: 93) con la implementación de políticas como las fumigaciones aéreas de cultivos ilícitos con herbicidas. La "recuperación” de las tierras dedicadas a los campos de coca y amapola significará su retorno al orden de la civilización. Puesto que el resultado comprobado es que esos campos son abandonados y los cultivos ilícitos trasladados a otra parte su retorno a la civilización no ocurre como cambio de su destino (a cultivos "lícitos", por ejemplo) sino como regeneración del bosque. Este hecho comporta una curiosa contradicción, resuelta en la lógica del capital postnacional: la recuperación civilizada de los campos cultivados con coca y amapola supone su retorno a la naturaleza.
} 
costa, aun a riesgo de crear competencias jurisdiccionales que ponen en cuestión la integridad de los Estados nacionales. De esta manera los nativos ecológicos se espacializan en territorios necesarios a la lógica cultural del capitalismo postmoderno y multicultural. Los nativos ecológicos cuidan los territorios biodiversos, situados en una nueva frontera levantada entre naturaleza y cultura por los discursos ambientalistas. El ambientalismo co-produce territorios étnicos e indianidad. Esta nueva segregación es aún mas insidiosa si a ella se suma el hecho de que a los indígenas confinados en los territorios biodiversos les está prohibida la contemporaneidad: el neo-esencialismo indigenista-que los indígenas aprovechan estratégicamente- los fija en un tiempo-espacio tradicional del cual sólo pueden escapar a riego de desindianizarse; la negación de la coetaneidad (sensu Fabian, 1983) se recicla en el proyecto multicultural. Esta paradoja histórica aumenta su contundencia bajo el lente comparativo: durante la modernidad los otros debían ser como nosotros (ese es el sentido del erotismo político del proyecto civilizador); en la era multicultural, en cambio, los otros no deben ser como nosotros.

La idea negativa de la naturaleza adquirió connotaciones positivas en el discurso occidental en las ideas relacionadas con el "buen salvaje", hijas del romanticismo, una clara oposición al capitalismo emergente. La connotación negativa de la naturaleza también se transmuta en positiva y afirmativa cuando se desplaza el locus de la enunciación fuera de los lugares hegemónicos tradicionales. La enunciación sobre el otro desde el locus étnico hizo de la naturaleza una virtud. La obra de Quintín Lame (2004) es un buen ejemplo en este sentido, la inversión subalterna de la dicotomía hegemónica. Su texto se estructura alrededor de la dicotomía naturaleza/cultura. Lame fue educado por la naturaleza, la única escuela válida, y no por la cultura:

\begin{abstract}
Yo no puedo enorgullecerme con sofismas de que hice detenidos estudios en escuela, en un colegio [...] porque la Naturaleza humana me ha educado como educó a las aves del bosque solitario que ahí entonan sus melodiosos cantos y se preparan para construir sabiamente sus casuchitas sin maestro: y le cantaron al indiecito cuando la misma Naturaleza me acariciaba y me regalaba flores, hojas y gotas de rocío (Lame, 2004: 146, 148).
\end{abstract}

\title{
Bien/mal
}

Los discursos sobre la alteridad étnica están atravesados por la idea maniquea del bien y del mal. En algunos de ellos, quizá la mayoría, el yo es bueno y el otro malo (el bien es la civilización; el mal el salvajismo). Las connotaciones negativas del otro fueron llenadas de sentido. Por ejemplo, la antropofagia fue un 
expediente de "desvalorización cultural" del otro en el marco de la dominación colonial. Como anotó Clastres refiriéndose a los Guayaki (1998: 311) "el canibal es siempre el otro." Una característica moderna es que la destrucción del mal se ve como un bien. El peso de ese archivo atraviesa los siglos con una coherencia aterradora desde la guerra justa contra los indios (Ginés de Sepúlveda, 1996) en el siglo XVI, hasta el derecho de intervención en nombre de universales hegemónicos, como la invasión de Iraq. Esa es una de las características más conspicuas del capitalismo y de la modernidad: la destrucción de todo lo que se les oponga es un acto bondadoso y altruista. Desde este punto de vista la destrucción de la cultura de los otros fue un bien que se les hizo en el camino hacia la civilización (Berman, 1988: 40). Las "pérdidas" culturales y de autonomía de los nativos no fueron nada comparadas con las ganancias que obtendrían con su entrada triunfal a la civilización (aunque siempre por la puerta de atrás y siempre para estar localizados en los aposentos de la servidumbre).

En esos discursos también hay lugar para que los "bienes" de la civilización sean vistos como un mal, como un aspecto diabólico y destructivo. Esta consideración destructiva de la modernidad hace que el malo (el otro) de pronto aparezca como bueno (el buen salvaje), como una proyección especular en la que debe mirarse la civilización. Este horizonte alimenta el indigenismo romántico y el indigenismo ecologista del capitalismo contemporáneo. Ese fue el discurso de Las Casas (1992) sobre la maldad de los encomenderos y la relativa bondad de los indios (sinónimo de su sujeción a la religión). El buen salvaje es una nostalgia por un orden perdido y por utopías sin realizar, precipitadas por los males sociales producidos por la civilización. El manifiesto de Lame (2004) también abundó sobre esa dicotomía, esta vez desde la enunciación nativa: los indios son buenos y los blancos malos. El equilibrio perdido por la maldad blanca sobre la bondad nativa sólo se podría recuperar a través de lo que llamó ley de la compensación, una suerte de males divinos que caerán sobre los atropelladores de su pueblo. No existen muchas razones, distintas de la idea de que la taxonomía occidental es un hallazgo universal y no un localismo globalizado, para pretender que la dicotomía bueno/malo también formara parte de los sistemas nativos de representación antes de su intervención por el aparato retórico colonial. ${ }^{10}$

\footnotetext{
${ }^{9}$ El canibalismo es una categoría moral que se despliega para localizar al otro. No importa tanto que los comportamientos canibales existan o no -lo más probable es que hayan existido ampliamente en la historia de la humanidad- sino su uso como catalogación del otro.

${ }^{10}$ Henman (1981: 195) señaló que las ideas del antropólogo Segundo Bernal sobre la magia y la medicina nasa (páez) usaron un maniqueismo (magia "buena" y hechicería "mala") inexistente en su cultura: "[...] la palabra páez para 'malo' - eumet- significa simplemente 'no bueno,' ya que la partícula met con frecuencia se usa como sufijo negativo en una gran cantidad de sustantivos y adjetivos. Por consiguiente dividir la magia páez entre practicantes 'buenos' y 'malos' tiene poco significado absoluto puesto que la percepción de dichos valores duales depende, obviamente, de la posición afectiva de cada uno en el conflicto en cuestión”.
} 


\section{La alteridad y sus auto-representaciones}

Una afirmación de Marx (1973: 490) en el Dieciocho brumario, refiriéndose a los campesinos parcelarios franceses - "no pueden representarse sino que tienen que ser representados"-, ha servido para señalar la arrogancia del representador que representa al representado porque asume que éste es incapaz de representarse a sí mismo. Esta arrogancia ha recurrido, una y otra vez, en la historia de la colonización. ${ }^{11}$ Los discursos sobre la alteridad son sistemas de representación, y éstos actos performativos de la colonización. Mignolo (1995) argumentó que el análisis de las representaciones en el marco del colonialismo debe centrarse en la semiosis colonial, el entendimiento de procesos e interacciones semióticas. Los análisis hechos desde un locus distanciado y exterior no captan el amplio rango de interacciones semióticas que tienen lugar en situaciones coloniales:

[...] la preocupación con la representación del colonizado se enfoca en el discurso del colonizador y olvida preguntar cómo se representa a sí mismo el colonizado, cómo se muestra y concibe a sí mismo sin necesidad de auto-designados cronistas, filósofos, misioneros y letrados que los representen, muestren y hablen por ellos (Mignolo, 1995: 332).

Ese llamado de atención resulta crucial para una arqueología de la alteridad porque lleva a prestar atención, entre otras cosas, a la manera como los otros se representan a sí mismos. Uno de los lugares retóricos donde ha ocurrido esa representación es la auto-etnografía. En la década de 1980 se consolidaron los movimientos sociales que reivindicaron la diferencia cultural, sobre todo los movimientos indígenas. El empoderamiento de la alteridad -dinamizando sus luchas contra las políticas integracionistas del Estado y reclamando el derecho a la diferencia y a la autonomía, acogiendo así el eco de la antropología militante y el indigenismo- incluyó el reto al monopolio narrativo de los etnógrafos y a su papel de intermediación cultural: ahora los otros podían hablar (escribir) por sí mismos. En las últimas dos décadas las comunidades indígenas han recurrido a la escritura como camino de expresión política y cultural. En este escenario el papel del etnógrafo indígena empezó a ser crucial, no sólo como traductor de la cultura de los otros -es decir, como intérprete de la relación cultural entre las comunidades, la sociedad nacional y el Estado- sino también de la cultura propia. En ese proceso se han escrito reflexiones etnográficas que rompen

\footnotetext{
${ }^{11}$ Un misionero belga, Placide Tempels, quien escribió un libro sobre la ontología Bantú desde la perspectiva de la filosofía occidental, señaló: "Nuestro trabajo es proceder a esa clase de desarrollo sistemático. Nosotros somos quienes podremos decirles, en términos precisos, cuál es su concepto más íntimo del ser" (citado por Mudimbe, 1988: 139).
} 
el monopolio narrativo de los expertos; se trata de etnografías de la alteridad hecha por los otros, sin intermediaciones. Las auto-etnografías movilizan el concepto de cultura, que antes fue la marca de fábrica (y el monopolio) de la antropología, de una manera prominente. La cultura de las auto-etnografías recogió el viejo traje esencialista desdeñado por los antropólogos en las dos últimas décadas y lo situó en el centro de la reflexión sobre la legitimidad, la coherencia y la viabilidad de la vida indígena. El esoterismo del uso antropológico de la cultura -un concepto para especialistas distanciados, en buena medida incomprensible para sus actores- dio paso a un uso generalizado, de base, que defiende, promueve y activa la autenticidad de la cultura indígena y la opone a la cultura (espuria, artificiosa) de los otros. Las auto-etnografías se construyen alrededor de la autenticidad cultural y hacen de ella la joya de la corona nativa. La cultura se convierte en un pilar básico de la etnicidad en la arena política; su dimensión instrumental opaca (en términos retóricos) su dimensión de sentido.

La cultura indígena representada en las auto-etnografías no es sujeto de indagación sino de exaltación unanimista y de elaboración como lugar básico desde el cual se dinamizan y legitiman las luchas étnicas. Las exigencias analíticas y críticas que la antropología constituyó como el canon de las etnografías disciplinarias desaparecen bajo la pureza (acrítica) de los cuadros idílicos y bucólicos pintados por las auto-etnografías. Sin embargo, el unanimismo tiene excepciones (cada vez más numerosas). Las auto-etnografías están siendo usadas como instrumentos de relativización, como espacio de análisis de la cultura y como instrumento de confrontación reflexiva rompiendo la superficie complaciente (pero argüiblemente necesaria) de la unanimidad cultural y encontrando contradicciones, dominios y hegemonías; encontrando, sobre todo, que la cultura no es un todo integrado y orgánico, ausente de diversidad y de tensiones internas - una construcción retórica del romanticismo culturalista-, sino un campo contestado alrededor del cual los actores sociales empiezan a indagar, cuestionar y construir.

\section{Escatología de la vida social}

La reflexión antropológica sobre las diferencias culturales comporta un horizonte escatológico, una sonda retórica que tiene la intención de imaginar el devenir. Su munición no es el pasado -que ha dejado de ser y cuya contemplación sólo tiene sentido como lugar de proyección-sino la postulación del futuro. ¿Qué habrá de ser de la vida social en pocos años, en algunas décadas?; ¿florecerá la violencia entre grupos cada vez más discriminados (desde afuera y desde adentro) 
a lo largo de vectores cada vez más culturales (cada vez menos económicos, aunque a veces coincidan; cada vez menos sexuales) o el orden transnacional impondrá una paz universal predicada sobre retóricas (los derechos humanos, el libre mercado) y violencias (el derecho de intervención, la guerra justa) globales?; ¿se disolverán las diferencias (que separan) y se formará una gran sociedad universal sobre unos principios éticos finalmente consensuados e innegociables (que unen) desde un orden jurídico inter-trans-supra-nacional (el derecho a la vida, al trabajo, al bienestar, a la autonomía)?

Colombia es un lugar más para imaginar escenarios posibles, pero no es un lugar particular cualquiera sino nuestro lugar, la plataforma de despegue y aterrizaje de nuestros cohetes discursivos. Imagino tres posibilidades distintas (excuso de antemano este ejercicio de acomodación). Una, preferida por el humanismo - ese residuo renacentista que promete recuperar el tiempo perdido de la igualdad, la libertad, el bienestar y la justicia, sacrificados sangrientamente en el altar del capitalismo-, imagina un mundo de iguales en el cual las semejanzas (deseadas y construidas desde universales categóricos) primarán sobre las diferencias (identificadas y eliminadas desde esos mismos universales). Otra, preferida por el multiculturalismo (el del Estado y el de muchos movimientos sociales), imagina un mundo de diferentes (separados); las diferencias también son deseadas y construidas desde universales categóricos. La tercera, la vía intercultural, promueve la diferencia pero sin destrozar los consensos mínimos que hacen posible la vida en común; promueve la tramitación y el diálogo entre las culturas, los entendimientos por encima de los atrincheramientos.

El humanismo cree que las diferencias culturales levantadas desde el discurso colonial y promovidas desde los movimientos sociales como lugar básico de empoderamiento y resistencia ${ }^{12}$ pueden dar paso a un mundo horizontal sin razas (¿sin clases?) en el cual la distribución de la riqueza y la justicia sea verdaderamente homogénea. Este utopismo humanista fue resumido por Jean-Paul Sartre (1985) en Orfeo negro, el texto que dedicó al naciente movimiento de negritudes:

En realidad la negritud aparece como el momento débil de una progresión dialéctica: la afirmación teórica y práctica de la supremacía blanca es la tesis; la posición de negritud con un valor antitético es el momento de negatividad. Pero este momento negativo no es suficiente en sí mismo y los negros que lo emplean lo saben perfectamente; saben que apunta a preparar la síntesis o la realización del ser humano en una sociedad sin razas. De ahí que la negritud esté a favor de destruirse a sí misma; es

\footnotetext{
${ }^{12}$ Nunca será demasiado redundante recordar esta extraordinaria paradoja histórica: las diferencias usadas para segregar y controlar desde lo alto de la pirámide jerárquica son las mismas armas que se usan desde su base para derribarla.
} 
un "camino hacia" y no una "llegada a", un medio y no un fin (Sartre, 1985: 327).

Para Sartre la síntesis de la dialéctica de las relaciones humanas hace necesario (quizás imperioso, sino inevitable) suponer una "sociedad sin razas"; por eso la negritud (o cualquier otro movimiento social) debería saber que el enfrentamiento esencialista es apenas pasajero, una estrategia necesaria (pero provisoria porque falible) que habrá de ser abandonada (¿cuándo?). En la misma guisa, en el Manifiesto del Partido Comunista (1973) Marx y Engels pensaron que el ascenso del proletariado a clase dominante por medio de la insurrección revolucionaria sería, apenas, un paso hacia la constitución de la sociedad sin clases:

Si en la lucha contra la burguesía el proletariado se constituye indefectiblemente en clase; si mediante la revolución se convierte en clase dominante y, en cuanto clase dominante, suprime por la fuerza las viejas relaciones de producción, suprime, al mismo tiempo que estas relaciones de producción, las condiciones para la existencia del antagonismo de clase y de las clases en general y, por tanto, de su propia dominación como clase (Marx, 1973: 130).

El humanismo también alimenta la obra de Said, uno de los teóricos más influyentes de las tres últimas décadas:

Los equivalentes seculares [del fundamentalismo] son un regreso al nacionalismo y a las teorías que subrayan la radical distinción (una distinción falsamente exhaustiva, creo) entre las distintas culturas y civilizaciones [...] uno de los grandes avances de la moderna teoría cultural es la comprensión, casi universalmente admitida, de que las culturas son híbridas y heterogéneas [...] las culturas y las civilizaciones están $\tan$ interrelacionadas y son tan interdependientes que es difícil realizar una descripción unitaria o simplemente perfilada de su individualidad [...] cualquier tentativa de encasillar a culturas y pueblos en castas y/o esencias separadas y diferentes está expuesto no sólo a los equívocos y las falsedades consiguientes sino, también, a que nuestra comprensión se alíe con el poder para crear cosas tales como "Oriente" y "Occidente" (Said, 2004: 455-456).

La disolución de la diferencia, el arribo al mundo de iguales que soñó el espíritu original de la modernidad, ignorando la incómoda existencia del colonialismo (su hermano gemelo), habrá de realizarse en un ecumenismo trascendente, parecido al que han venido predicando algunos teólogos católicos, demasiado progresistas para los ojos vigilantes (y segregacionistas) de la Iglesia. Pero ese ecumenismo debe responder preguntas elementales: ¿desde dónde es enunciado?, ¿por quién?; ¿por un altruismo que elude los avatares del orden multinacional, marcadamente 
colonialista? Esas preguntas no pueden ser respondidas sin eliminar el principio rector del relativismo cultural, edificado sobre dos presupuestos mínimos: (a) las culturas son inconmensurables; y (b) cada cultura tiene el derecho de establecer sus propios referentes simbólicos. Cualquier ecumenismo, no importa qué tan bien intencionado, se levanta sobre principios hegemónicos que sacrifican las diferencias en el altar del consenso o, lo que es más frecuente, en la sangría de la imposición ideológica. Probablemente esa fue la razón que llevó a Frantz Fanon (1967) a rechazar la plataforma humanista propuesta por Sartre para el movimiento de negritudes. Para Fanon éste no era un punto intermedio en el camino sino el lugar de llegada, la única defensa posible contra siglos de subordinación, explotación y humillación. Fanon creyó que el ecumenismo humanista sacrificaría el derecho a la diferencia reivindicado y alcanzado por los pueblos colonizados y establecería criterios universales de igualdad (pero occidentales, al fin y al cabo) que pasarían por encima de las particularidades deseadas.

La retórica multicultural también descree de la igualdad humanista y alimenta y se refugia en un esencialismo estratégico que supon, como un hecho, las diferencias culturales y las promueve. Si la heterogeneidad es constitutiva del nuevo orden social, de la multiculturalidad y la plurietnicidad, ¿qué puede mantener a esta sociedad unida? La respuesta del Estado es simple (y vieja): el monopolio del poder por un sector (cultural) específico es la precondición esencial para el mantenimiento de la sociedad total (Trouillot, 1991: 23). El multiculturalismo no incluye a los otros como mestizos sino como miembros diferenciados de la comunidad "nacional" multicultural y pluriétnica. La respuesta de los movimientos sociales es distinta y apuesta por una suerte de laissez faire cultural: la alteridad florecerá $-\mathrm{y}$, con ella, la mejoría de las condiciones de vida de los sujetos diferentes- en los espacios creados por la retórica multicultural, incluso corriendo el riesgo de caminar por la cornisa.

La interculturalidad está, de alguna manera, a medio camino entre el humanismo y el multiculturalismo. Cree, como el primero, en la existencia de consensos mínimos -aunque, repito, estos siempre serán hegemónicos- que deberán ser establecidos a través de la discusión democrática; y cree, como el segundo, que las diferencias deben ser respetadas, tramitadas y promovidas. Cree, en suma, que el orden social hegemónico y desigual puede ser modificado o reformado para que la igualdad de la diferencia se realice, para que alteridad y mismidad se encuentren en un escenario horizontal, plural, no jerárquico.

En estas tres posibilidades (y, quizás, en otras) se juega la relación entre mismidad y alteridad. Espero haber mostrado que una antropología de la alteridad 
es, también, una reflexión sobre la vida social que el enunciador considera suya. Espero haber mostrado que la antropología, una disciplina que indaga por las redes de significación que llamamos culturas, no puede desentenderse de esa relación porque estaría condenada a dar la espalda a sucesos contemporáneos que eran desconocidos (e impensables) hace pocos años. La antropología de esta época debe estar a tono con los tiempos. Debe estar, en suma, dispuesta a dejar la piel en la lucha por la construcción de un mundo mejor.

\section{Bibliografia}

- Appadurai, Arjun, 2001, La modernidad desbordada, Dimensiones culturales de la globalización, México: Trilce-Fondo de Cultura Económica.

- Bartra, Roger, 1998, El salvaje en el espejo, México: Era.

- Berman, Marshall, 1988, Todo lo sólido se desvanece en el aire, México: Siglo XXI.

- Bernstein, Richard, 1983, Beyond objectivism and relativism, Oxford: Blackwell.

Bolaños, Álvaro Félix, 1994, Barbarie y canibalismo. Los indios pijaos de fray Pedro Simón, Bogotá: CEREC.

- Casement, Roger, 1997, The Amazon journal, Dublín: The Lilliput Press.

- Castro, Santiago, 2005, La poscolonialidad explicada a los niños, Popayán: Universidad del Cauca.

- Céline, Louis Ferdinand, 1984, Viaje al fin de la noche, Bogotá: Seix BarralOveja Negra.

- Clastres, Pierre, 1998, Chronicle of the guayaki indians, Nueva York: Zone Books.

- Clifford, James, 1992, The predicament of culture, Cambridge: Harvard University Press.

- Cobo, Juan Gustavo, 1973, "La poesía de Álvaro Mutis," en: Mutis, Alvaro, Summa de Maqroll el Gaviero, pp. 7-52. Barcelona: Seix Barral.

- Conrad, Joseph, 1980, El corazón de las tinieblas, Barcelona: Lumen.

- Dussell, Enrique, 1994, El encubrimiento del otro, Quito: Abya-Yala. 
- Elias, Norbert, 1993, El proceso de la civilización, México: Fondo de Cultura Económica.

- Enaudeau, Corinne, 1999, La paradoja de la representación, Buenos Aires: Paidós.

- Espinosa, Myriam Amparo, 2002, "Contraste entre miradas colonizadoras y subalternas sobre el Plan Colombia”, en: Chiapas 13, pp. 87-98.

- Fabian, Johannes, 1983, Time and the other, Nueva York: Columbia University Press.

- Fanon, Frantz, 1967, Black skin, white masks, Nueva York: Grove Press.

- Foucault, Michel, 1985, Las palabras y las cosas, Barcelona: PlanetaAgostini.

- Friedman, Jonathan, 1994, Cultural identity and global process, Londres: Sage.

- Gadamer, Hans-Georg, 1992, Verdad y método, volumen 2, Salamanca: Sígueme.

- Giddens, Anthony, 1979, Central problems in social theory, Londres: MacMillan.

- Ginés de Sepúlveda, Juan, 1996, Tratado sobre las justas causas de la guerra contra los indios, México, FCE. [1941].

- Helms, Mary, 1988, Ulysses sail: an ethnographic odyssey of power, knowledge, and geographic distance, Princeton: Princeton University Press.

- Helms, Mary, 1991, "Esoteric knowledge, geographic distance, and the elaboration of leadership status: dynamics of resource control", en: Rambo, Terry y Karl Gillogly (eds.), Profiles in cultural evolution, Ann Arbor: University of Michigan, pp. 333-350.

- Henman, Anthony, 1981, Mama coca, El Áncora-Oveja Negra, Bogotá.

Jones, Sian. 1997. The archaeology of ethnicity. Londres: Routledge.

- Lame, Manuel Quintín, 2004, Los pensamientos del indio que se educó dentro de las selvas colombianas, Popayán: Biblioteca del Gran Cauca. [1971].

- Las Casas, Bartolomé de, 1992, Brevísima relación de la destruición de las Indias, Madrid: Tecnos. [1552].

- Leclercq, Gerard, 1973, Antropología y colonialismo, Madrid: Alberto Corazón. 
- Marx, Karl, 1973, “El dieciocho Brumario de Luis Bonaparte”, en: Obras escogidas de C. Marx y F. Engels, Tomo I, pp. 408-498. Moscú: Editorial Progreso.

- Marx, Karl y Friedrich Engels, 1973, "Manifiesto del Partido Comunista", en: Obras escogidas de C. Marx y F. Engels, Tomo I, pp. 110-140. Moscú: Editorial Progreso.

- Mignolo, Walter, 1995, The darker side of the Renaissance. Literacy, territoriality, and colonization. Ann Arbor: University of Michigan Press.

- Mudimbe, Valentin, 1988, The invention of Africa, Bloomington: Indiana University Press.

- Nader, Laura, 1996, "Anthropological inquiry into boundaries, power, and knowledge", en: Nader, Laura (ed.), Naked science, Londres: Routledge, pp. $1-25$.

- Quijano, Aníbal, 1990, Modernidad, identidady utopía en América Latina, Quito: Editorial El Conejo.

- Reichel-Dolmatoff, Gerardo, 1977, "El misionero ante las culturas indígenas", en: Estudios antropológicos de Gerardo y Alicia Reichel-Dolmatoff, Bogotá: Instituto Colombiano de Cultura, pp 421-432.

- Said, Edward, 2004, Orientalismo, Barcelona: Random House Mondadori.

- Sartre, Jean-Paul, 1985, Escritos sobre literatura, Madrid: Alianza Editorial.

- Taussig, Michael, 1987, Shamanism, colonialism, and the wild man. A study in terror and healing, Chicago: University of Chicago Press.

- Taussig, Michael, 1993, Mimesis and alterity, Londres: Routledge.

- Toulmin, Stephen, 2001, Cosmópolis. El trasfondo de la modernidad, Barcelona: Península.

- Trouillot, Michel-Rolph, 1991, "Anthropology and the savage slot: the poetics and politics of otherness", en: Fox, Richard, (ed.), Recapturing anthropology, pp. 17-44, Santa Fe: SAR.

- Trouillot, Michel-Rolph, 1995, Silencing the past. Power and the production of bistory, Boston: Beacon Press.

- Ulloa, Astrid, 2004, El nativo ecológico, Bogotá: Instituto Colombiano de Antropología e Historia.

- Whiffen, Norman, 1915, The north-west Amazons: notes of some months spent among cannibal tribes, Londres: Constable. 
